\title{
Bilateral parotid sialolithiasis in a patient with acquired immunodeficiency syndrome and immunoglobulin $G$ multiple myeloma
}

\author{
Fabrizio Ottaviani, MD, ${ }^{\mathrm{a}}$ Alessandra Galli, MD, ${ }^{\mathrm{a}}$ Mothanje Barbara Lucia, MD, ${ }^{\mathrm{b}}$ and \\ Giulio Ventura, MD, ${ }^{b}$ Rome, Italy \\ CATHOLIC UNIVERSITY
}

\begin{abstract}
Bilateral multiple parotid calculi, which are uncommonly diagnosed in the normal population, have never been reported in patients infected with human immunodeficiency virus. Herein we report a case of bilateral parotid sialolithiasis in a patient who had acquired immunodeficiency syndrome and was affected by multiple myeloma. The possible etiopathogenesis in view of the alterations of immunity, oral $\mathrm{pH}$, and salivary composition that are observed in multiple myeloma and in human immunodeficiency virus infection are discussed. (Oral Surg Oral Med Oral Pathol Oral Radiol Endod 1997;83:552-4)
\end{abstract}

Swelling of the major salivary glands is frequently observed in patients with human immunodeficiency virus (HIV) infection and may be related to acute sialoadenitis or to HIV salivary gland disease including lymph node enlargement, lymphomas, Kaposi's sarcoma, benign lymphoepithelial lesions, and cysts. ${ }^{1,2}$ Parotid gland swelling has recently been reported as a consequence of cytomegalovirus infection. ${ }^{3,4}$ To date, however, no cases of sialolithiasis have been reported in HIV-infected patients.

In the general population, most salivary stones occur in the submandibular gland $(80 \%$ to $90 \%)$, whereas $5 \%$ to $20 \%$ are found in the parotid gland. ${ }^{5}$ The sublingual gland and the minor salivary glands are rarely affected. The right and left sides are equally affected, whereas bilateral sialolithiasis is rare. When parotid glands are involved, calculi are most often single and located within the ductal system; intraparenchymal sialoliths are rarely diagnosed. In 1978 Perrotta et al. ${ }^{6}$ described two cases of bilateral multiple calculi located in the parotid parenchyma, one of their own observation and the other previously reported by Schubert et al. ${ }^{7}$ in 1976. In the same year Ayani et al. ${ }^{8}$ reported a case of parenchymal parotid calculi, although the disease was monolateral. Later, in 1979 , Fesharaki et al. ${ }^{9}$ reported a case in a 10year-old girl. In the latter case, however, surgery revealed seven calculi within the gland parenchyma. In a series of 1200 cases of major salivary glands lith-

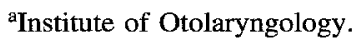

${ }^{\mathrm{b}}$ Institute of Infectious Diseases.

Supported in part by grant $60 \%$ no. 7020754 , Murst, Italy.

Received for publication June 11, 1996; revised July 19, 1996; accepted Dec. 2, 1996.

Copyright $(\mathcal{O}$ by Mosby-Year Book, Inc.

$1079-2104 / 97 / \$ 5.00+0$ 7/13/79957
}

iasis reviewed by Seifert et al. ${ }^{10}$ in 1992 , parotid calculi did not exceed $10 \%$, with a ratio for parenchymal and ductal episodes of 1:35. This finding means that parotid calculi located in the gland tissue occurs in 3 out of 120 cases.

We describe a case of bilateral parotid calculi that occurred in a patient with acquired immunodeficiency syndrome and immunoglobulin $G$ multiple myeloma. Changes in salivary glands function, saliva chemical composition, and oral $\mathrm{pH}$ that may develop during the course of HIV infection are also discussed.

\section{CASE REPORT}

A 38-year-old HIV-positive man with a previous clinical history of Pneumocystis carinii pneumonia and recurrent episodes of oral and esophageal candidiasis was admitted to our University Hospital in September 1994 because of irregular fever, malaise, myalgias, arthralgias, headache, and persistent bone pain. He also reported bilateral swelling of the parotid glands, which had begun 3 years earlier and gradually increased in size. Before hospitalization the patient had been taking oral co-trimoxazole and fluconazole daily for 8 months. He had also been taking oral zidovudine for 2 months, which had to be interrupted because of anemization.

On admission the patient was febrile $\left(38.5^{\circ} \mathrm{C}\right)$, dehydrated, and cachectic. Inspection revealed facial asymmetry caused by bilateral enlargement of the parotid glands, which was more conspicuous on the right side. Both glands were hardened but not fixed, painful on palpation, and covered by normal skin. Calcifications were not detectable on palpation bilaterally. The intraoral examination was normal apart from a number of diffuse small patches of easily removable white plaques, typical of pseudomembranous oral candidiasis, on tonsillar arches and the anterior tip of the tongue.

Laboratory findings showed a hemoglobin level of 10 $\mathrm{gm} / \mathrm{dl}$, a leukocyte count of $2,500 / \mathrm{mm}^{3}$, and a platelet count of $250,000 / \mathrm{mm}^{3}$. The CD4+ lymphocyte count was $10 /$ 

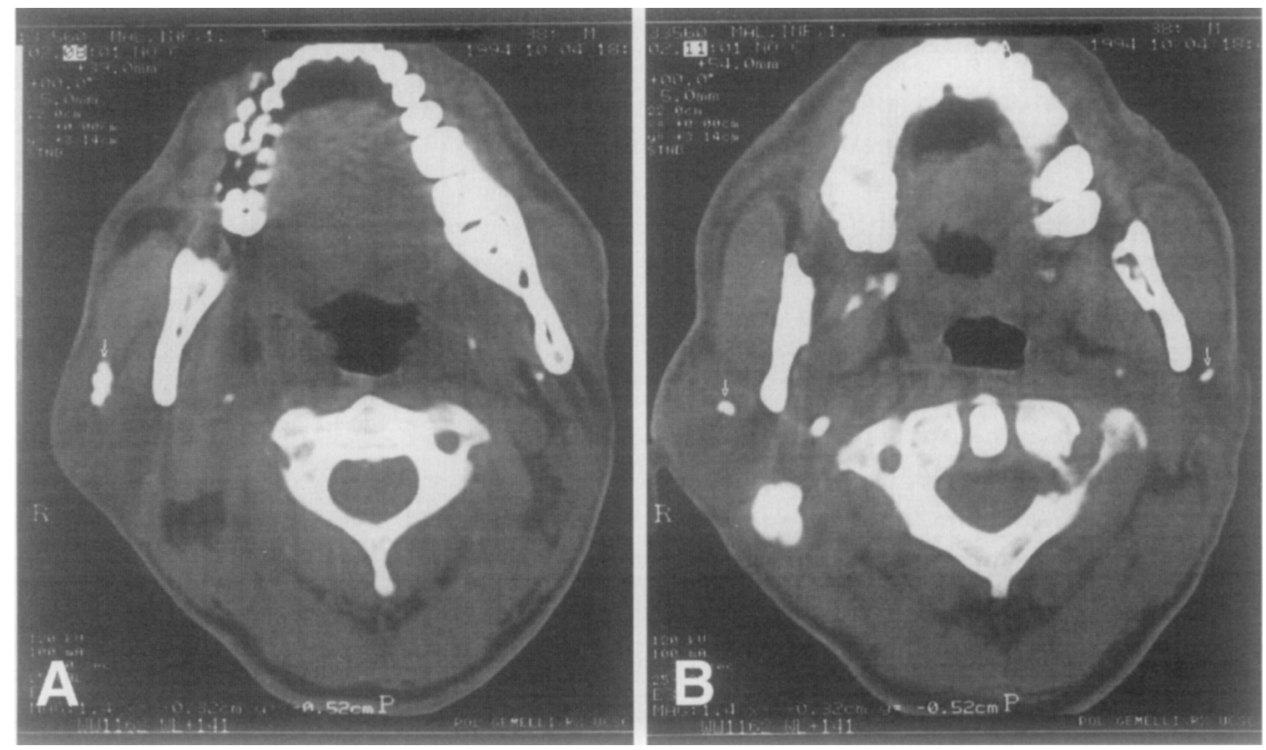

Fig. 1. Computed tomography scan showing large stone within homogeneous swelling of right parotid gland (A); in another slice, stone is also present in left parotid gland (B).

$\mathrm{mm}^{3}$. The total protein was $9.3 \mathrm{gm} / \mathrm{dl}$, and the calcium level was $9.9 \mathrm{mg} / \mathrm{dl}$. Serum protein electrophoresis and immunoelectrophoresis revealed an immunoglobulin G-k monoclonal spike. Urine protein immunoelectrophoresis disclosed the presence of free k-light chains. Bone marrow biopsy showed increased plasma cells that were polyclonal for $\boldsymbol{\kappa}$ - and $\lambda$-light chains. A biopsy of a lytic femural lesion showed a highly malignant infiltrate composed of atypical plasma cells; a diagnosis of multiple myeloma was established. The results of chest $\mathrm{x}$-ray evaluation were unremarkable. Ultrasound examination of the right parotid gland showed a nonhomogeneous solid mass $(3.5 \times 2 \mathrm{~cm})$ containing a number of small stones. The left parotid gland appeared normal. A computed tomography scan of the neck confirmed the presence of calculi in the right parotid gland and disclosed the presence of very small calcifications also on the left side (Fig. 1). A fine-needle biopsy of the right parotid gland did not reveal any major histologic alteration. On the basis of both clinical and radiologic findings, a diagnosis of bilateral parotid sialolithiasis was made. Chemotherapy with melphalan and prednisone was started for multiple myeloma treatment. However, the patient suddenly died 2 weeks later.

\section{DISCUSSION}

Salivary stones are mainly composed of calcium oxalate and calcium phosphate associated with a thickened mucus and cellular debris. ${ }^{11}$ In this case the gland duct length and position, the chemical composition of the saliva, and a slow or reduced salivary. flow rate ${ }^{12}$ were considered in the cause and pathogenesis of salivary stones.

A number of salivary functional changes other than HIV salivary gland disease have been reported in
HrV-infected individuals. Yeh et al. ${ }^{13}$ observed a significant reduction in the salivary flow rates of parotid and submandibular/sublingual glands after stimulation. Mandel et al. ${ }^{12}$ reported similar results in stimulated parotid glands, whereas Atkinson et al. ${ }^{14,15}$ found a significant decrease in saliva output in stimulated submandibular and sublingual glands. Alterations in the saliva chemical composition such as increased sodium and chloride and lysozyme, peroxidase, lactoferrine, and immunoglobulin A levels $^{12,13,15}$ have also been reported as a result of HIV infection.

Such alterations do not seem to depend on either commonly found viruses such as cytomegalovirus or other opportunistic pathogens such as Candida albicans. ${ }^{16}$ Longitudinal studies have confirmed an increase of specific salivary components such as proteins and electrolytes, which parallels HIV disease progression. ${ }^{15}$

The parotid saliva $\mathrm{pH}$ is known to be lower than that of the submandibular saliva (5.2 to 6.2 vs 6.1 to 7.5). ${ }^{17,18}$ This local condition may account for the precipitation of octacalcic phosphate seen inside the parotid gland.

The possible role of major systemic or metabolic diseases in the development of sialolithiasis in patients without HIV infection is still unknown. Indeed, the incidence of sialolithiasis is not significantly increased in patients with nephrolithiasis. ${ }^{19}$ In fact, although hypercalcemia is an important etiologic factor for nephrocalcinosis and uroliths formation, its effect on the major salivary glands seems quite weak 
as shown by Epivatianos et al. ${ }^{20}$ in rats. These authors suggest that in hypercalcemia the calcium metabolism is still ruled by the autonomic nervous system, thus preventing the formation of stones in salivary glands.

This finding may explain why sialolithiasis has not been reported in patients with multiple myeloma, in whom secondary hypercalcemia is very frequent. ${ }^{21}$ Moreover, in our patient the calcium level was normal.

In HIV infection the salivary flow is reduced, ${ }^{1}$ and the saliva protein content is increased. ${ }^{15}$ This trend is enhanced by oral candidiasis, which determines the highest concentrations of lysozyme and histidine-rich proteins (histatins). ${ }^{14}$ Despite this, no cases of multiple sialolithiasis in HIV-infected patients have to our knowledge been reported in the literature.

Because multiple myeloma may alter the saliva chemical composition as a result of an increase of the immunoglobulins delivered into the salivary secretions, ${ }^{22}$ we hypothesize that the alterations caused by both multiple myeloma and HIV infection may have induced the formation of multiple salivary calculi. Unfortunately, the collection of saliva for analysis was made impossible by the patient's sudden death.

The authors thank Dr. Attila Kovacs and Mr. Maurizio Cianfanelli for their kind help in doing bibliographic data research.

\section{REFERENCES}

1. Schiodt M. HTV-associated salivary gland disease: a review. Oral Surg Oral Med Oral Pathol 1992;73:164-7.

2. Zeitlen S, Shaha A. Parotid manifestations of HIV disease. J Surg Oncol 1991:47:230-2.

3. Wax TD, Layfield LJ, Zaleski S, Bhargara V, Cohen M, Lyerly HK, et al. Cytomegalovirus sialadenitis in patients with the acquired immunodeficiency syndrome: a potential diagnostic pitfall with fine-needle aspiration cytology. Diagn Cytopathol 1994;10:169-72.

4. Van Vooren JP, Farber CM, Daelemans P, Delforge ML, Liesnard C. Acute Sjogren-like syndrome as the first manifestation of generalized CMV infection in a patient with AIDS. J Laryngol Otol 1995;109:113-4.

5. Lustmann J, Regev E, Melamed Y. Sialolithiasis: a survey on
245 patients and a review of the literature. Int J Oral Maxillofac Surg 1990;19:135-8.

6. Perrotta RJ, Williams JR, Selfe RW. Simultaneous bilateral parotid and submandibular gland calculi. Arch Otolaryngol 1978;104:469-70.

7. Schubert Von J. Doppelseitige Steinbild in der Glandula Parotis. Stomatologie DDR 1976;26:265-8.

8. Ayani N. Multiple salivary calculi of the parotid gland. Otolaryngology (Tokyo) 1978;50:59-62.

9. Fesharaki R, Baloochy M, Sonbolastan M, Fotuhi A. Parotid gland calculi: report of a case. J Laryngol Otol 1979;93:737-9.

10. Seifert G, Miehlke A, Haubrich J, Chilla R. Diseases of the salivary glands: pathology, diagnosis, treatment, facial nerve surgery. Stuttgart, Germany: Georg Thieme Verlag, 1986:8590.

11. Hiraide F, Nomura Y. The fine surface structure and composition of salivary calculi. Laryngoscope 1980;90:152-8.

12. Mandel ID, Turgeon L, Barr CE. Parotid fluid flow-rate and composition in HIV infection. [abstract]. J Dent Res 1990;69:301.

13. Yeh CK, Fox PC, Ship JA, Busch KA, Bermudez DK, Wilder AM, et al. Oral defense mechanisms are impaired early in HIV-1 infected patients. J AIDS 1988;1:361-6.

14. Atkinson JC, Yeh CK, Oppeiheim FG, Bermudez D, Baum BJ. Elevation of salivary antimicrobial proteins following HIV-1 infection. J AIDS 1990;3:41-8.

15. Atkinson JC, Yeh CK, Bermudez D, Fox PC, Baum BJ. Longitudinal elevation of major salivary gland function in HIV-1 infected patients. J Oral Pathol Med 1989;18:469-70.

16. Marder MZ, Barr CE, Mandel ID. Cytomegalovirus presence and salivary composition in acquired immunodeficiency syndrome. Oral Surg Oral Med Oral Pathol 1985;60:372-6.

17. MeCann HG. Inorganic components of salivary secretion. In: Harris RS, editor. Art and science of dental caries research. New York: Academic Press, 1968:55-70.

18. Burstein LS, Boskey AL, Tannenbaum PS, Posner AS, Mandel ID. The crystal chemistry of submandibular and parotid salivary gland stones. J Oral Pathol 1979;8:284-91.

19. Isacson $G$, Lundquist $P G$. Salivary calculi as an aetiological factor in chronic sialo-adenitis of the submandibular gland. Clin Otolaryngol 1982;7:231-6.

20. Epivatianos A, Tsougas M. The effect of the hypercalcemia on the major salivary glands of the rat. Stomatologia Athenai 1991;47:306-13.

21. Kyle RA. Multiple myeloma: review of 869 cases. Mayo Clin Proc 1975;50:29-40.

22. Lajos J, Koman A, Boromissza E, Rojti M. Investigation of saliva immunoglobulins in monoclonal gammopathies. Ann Immunol Hung 1974;18:99-104.

Reprint requests:

Dr. Fabrizio Ottaviani

Institute of Otorhinolaryngology of the Catholic University of the

Sacred Heart

Largo A. Gemelli, 8

I-00168 Rome

Italy 